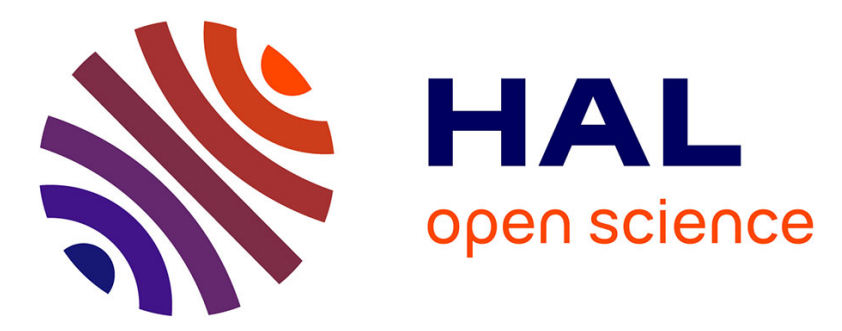

\title{
Preconcentration modeling for the optimization of a micro gas preconcentrator applied to environmental monitoring
}

El Hadji Malick Camara, Philippe Breuil, Danick Briand, Jean-Paul Viricelle, Christophe Pijolat, Nicolaas F de Rooij

\section{To cite this version:}

El Hadji Malick Camara, Philippe Breuil, Danick Briand, Jean-Paul Viricelle, Christophe Pijolat, et al.. Preconcentration modeling for the optimization of a micro gas preconcentrator applied to environmental monitoring. Analytical Chemistry, 2015, 87 (8), pp.4453-4463. 10.1021/acs.analchem.5b00400 . hal-01144264

\author{
HAL Id: hal-01144264 \\ https://hal.science/hal-01144264
}

Submitted on 23 Apr 2015

HAL is a multi-disciplinary open access archive for the deposit and dissemination of scientific research documents, whether they are published or not. The documents may come from teaching and research institutions in France or abroad, or from public or private research centers.
L'archive ouverte pluridisciplinaire HAL, est destinée au dépôt et à la diffusion de documents scientifiques de niveau recherche, publiés ou non, émanant des établissements d'enseignement et de recherche français ou étrangers, des laboratoires publics ou privés. 


\title{
Preconcentration modelling for the optimization of a micro gas pre- concentrator applied to environmental monitoring.
}

\author{
Malick Camara $^{\dagger}$, Philippe Breuil ${ }^{* *}$, Danick Briand ${ }^{\dagger}$, Jean-Paul Viricelle ${ }^{\ddagger}$, Christophe Pijolat ${ }^{\ddagger}$, Nico F. \\ de Rooij ${ }^{\dagger}$. \\ ${ }^{\dagger}$ Ecole Polytechnique Fédérale de Lausanne (EPFL), Institute of Microengineering (IMT), Sensors, Actuators and Microsys- \\ tems Laboratory (SAMLAB), Maladière 71b, 2000 Neuchâtel, Switzerland \\ ${ }^{\ddagger}$ Ecole Nationale Supérieure des Mines, SPIN-EMSE, PRESSIC-Department, CNRS: UMR5307, LGF, 42023 Saint- \\ Etienne, France
}

\begin{abstract}
This paper presents the optimization of a micro gas preconcentrator ( $\mu$-GP) system applied to atmospheric pollution monitoring, with the help of a complete modeling of the preconcentration cycle. Two different approaches based on kinetic equations are used to illustrate the behavior of the micro gas preconcentrator for given experimental conditions. The need of a high adsorption flow and heating rate, a low desorption flow and detection volume is demonstrated through this paper. Preliminary to this optimization, the preconcentration factor is discussed and a definition is proposed.
\end{abstract}

\section{INTRODUCTION}

In our previous studies, a Micro gas preconcentrator ( $\mu-\mathrm{GP})$ for the detection of Volatile Organic Compounds (VOCs) in trace level has been developed [1, 2, 3]. During these studies, we observed that the efficiency of this device was closely linked to four keys parameters such as the adsorption and desorption flow rates, desorption heating rate and detection volume; hence the idea to optimize these parameters through a complete modeling of the preconcentration from few experiments. Different couples of adsorbent-adsorbed gas can be simulated in order to predict the behavior of our device when it is used in defined conditions. In addition, this modeling allows as much to determine the breakthrough time $[4,5]$ in order to describe the desorption peak aspect and therefore to quantify the preconcentration performance. The particularity of this modeling is related to the fact that it treats the preconcentration system as a whole while the current models $[6,7,8]$ propose only to treat separately the adsorption with the desorption or the detection.

\section{PRECONCENTRATION FACTOR (PF)}

\section{Definition of preconcentration factor (PF)}

The efficiency of a given preconcentration device is estimated in term of PF which is defined in many ways through the literature. Nevertheless, the common point of all these definitions is its dependence on several parameters such as the sharp and volume of preconcentrator, the adsorption and desorption flows, the pressure drop and the heating rate.

Some authors $[9,10,11]$ define the PF as the ratio between peaks area obtained with and without preconcentrator ("chromatography approach"). This approach supposes to have a peak even without preconcentrator, i.e. a minimum of adsorption, which is not evident to see or measure when we are fac- ing with compounds in trace level. So, this definition would be in some cases inaccurate because of the necessity of having a detection peak even without preconcentrator.

Since the preconcentrator acts like a "concentration" amplifier, it seems more natural to define the PF as an amplification gain corresponding to the ratio between the maximal concentration measured after preconcentration and the mean concentration of the target compound before preconcentration.

\section{Maximization of the PF}

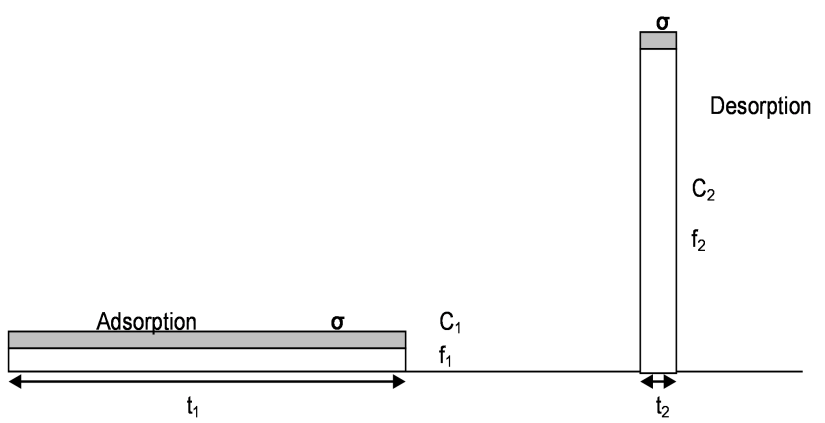

Figure 1: Schematic diagram of a preconcentration cycle, in grey the noise $\sigma$.

In order to evaluate and optimize the PF, we will first use a very simplistic model of the desorption, where the desorbing phase is a slot of high concentration (Figure 1).

For given preconcentration unit, the adsorption-desorption steps could be defined by six key parameters $C_{1}, f_{1}, t_{1}$ and $\mathrm{C}_{2}$, $f_{2}, t_{2}$ which correspond to the concentration $\left(\mathrm{C}_{\mathrm{i}}\right)$, the flow rate $\left(\mathrm{f}_{\mathrm{i}}\right)$ and the duration $\left(\mathrm{t}_{\mathrm{i}}\right)$ of the adsorption (1) and desorption (2) phases, respectively (Figure 1). The mass conversation during the preconcentration is characterized by the equation: 


$$
C_{1} \cdot f_{1} \cdot t_{1}=C_{2} \cdot f_{2} \cdot t_{2}
$$

Therefore, the PF defined as the ratio between concentrations after $\left(\mathrm{C}_{2}\right)$ and before $\left(\mathrm{C}_{1}\right)$ preconcentration is given by

$$
k=\frac{C_{2}}{C_{1}}=\frac{f_{1} \cdot t_{1}}{f_{2} \cdot t_{2}}
$$

According to the formula 2, for maximizing the PF one will need:

- A high adsorption flow rate $\left(f_{1}\right)$;

- A low desorption flow rate $\left(\mathrm{f}_{2}\right)$;

- A sufficiently long adsorption time $\left(\mathrm{t}_{1}\right)$;

- And a very short desorption time meaning a high heating rate $\left(\mathrm{t}_{2}\right)$.

In summary, the preconcentrator performance increases proportionally with $f_{1}$ and $t_{1}$ and decreases with $f_{2}$ and $t_{2}$. Since a short analytical duty cycle (i.e short adsorption time, $t_{1}$ ) is required for most safety and security applications, the highest flow rate possible is needed for compensating the reduction of the adsorption time $\left(t_{1}\right)$. The reduction of the desorption time $\left(\mathrm{t}_{2}\right)$ passes inevitably through a flash desorption of the adsorbed compound which is possible only with a high heating rate of the device. This high heating rate involves either a large heating power, a very low mass and therefore a miniaturized device. Furthermore, a low desorption flow rate $\left(f_{2}\right)$ is desired for maximizing the preconcentration factor. However, this flow cannot be reduced indefinitely due to the sampling volume of the detection system.

In theory, the maximum PF reachable with a given $\mu$-GP could be estimated following the ratio between the entire volume of target compound injected during the adsorption phase and the total volume of the preconcentrator (including adsorbent chamber, pipes and detector). But this value is difficult to reach because of the inevitable losses of transport and the sampling volume of the detector.

Although the detector is a separate element of the system, its sampling volume is an important parameter for the preconcentration performance. Indeed, the volume of the preconcentrator has to be in same order of magnitude as the sampling volume of the detection system for avoiding any dilution inconvenient after the desorption of the preconcentrator.

\section{Influence of the noise}

However, the main purpose of using a trace detection system is to achieve a low detection which is characterized by the limit of detection (LOD). The LOD is proportional to the standard deviation (noise) for a signal close to zero. In general, the noise can be considered as constant all along the experiment. So in first approximation, the LOD is inversely proportional to the PF since the latter increases with the signal-tonoise ratio (Table 1a).

Indeed, the noise of the detector can be reduced by applying a low pass filter such as averaging the largest number of measurements possible. The average standard deviation is the ratio between the standard deviation of a single measurement and the square root of the total number of measurements, $\mathrm{N}$ (with some statistical conditions). Since the number of measurements, $\mathrm{N}$, is fixed by the acquisition time $\Delta \mathrm{t}$ (time interval between two averaged measurements), therefore the noise could be expressed as a function inversely proportional to the square root of $\Delta \mathrm{t}$ (Table $1 \mathrm{~b}$ ). In fact, the signal of the detector is not constant during the desorption phase and would be integrated during a period of time, $t_{2}$.

Table 1: Signal-to-noise ratio (R) before and after preconcentra-

\begin{tabular}{|c|c|}
\hline $\begin{array}{c}\text { Before preconcentration } \\
\text { Single measurement }\end{array}$ & $\begin{array}{c}\text { After preconcentration } \\
\text { Single measurement }\end{array}$ \\
\hline$R_{0}=\frac{C_{1}}{\sigma}$ & $R=\frac{C_{2}}{\sigma}=k R_{0}$ \\
\hline
\end{tabular}

tion in the cases of single (a) and averaged multiple measurements (b). ( $\Delta \mathrm{t}$, time interval between two averaged measurements)

a)

\begin{tabular}{|c|c|}
\hline $\begin{array}{c}\text { Before preconcentration } \\
\text { Multiple measurements }\end{array}$ & $\begin{array}{c}\text { After preconcentration } \\
\text { Multiple measurements }\end{array}$ \\
\hline$R_{0}^{\prime}=\frac{C_{1}}{\sigma} \sqrt{\frac{t_{1}}{\Delta t}}$ & $R^{\prime}=\frac{C_{2}}{\sigma} \sqrt{\frac{t_{2}}{\Delta t}}=R_{0}^{\prime} \sqrt{\frac{t_{1}}{t_{2}}} \frac{f_{1}}{f_{2}}<k R_{0}^{\prime}$ \\
\hline
\end{tabular}

b)

\section{EXPERIMENTS CONDITIONS}

\section{Micromachined preconcentrator}

The preconcentrators used in this work consist in a small preconcentration chamber with an area of $10 \times 15 \mathrm{~mm}^{2}$ and a depth of $325 \mu \mathrm{m}$. The depth of the micro-channel was fixed at 325 $\mu \mathrm{m}$ for easing the insertion of fluidic capillaries which have an external diameter equivalent to this depth. The preconcentrators were silicon micromachined using deep reactive ion etching (DRIE) and sealed with glass cover. Three different shapes (neutral, zigzag and straight) were designed for testing and improving the flow distribution and also for facilitating the deposition of the absorbent within the device [3]. However, only the neutral design (without structures in the preconcentration chamber) was used in the experiments for avoiding any influence of structures within the preconcentration chamber. Since the device was developed for targeting environmental applications, in particular benzene detection, a carbon nanopowder (from Sigma-Aldrich; CAS number 7440-44-0) has been identified as an adequate adsorbent material because of its high adsorption capacity towards benzene and also its relatively low desorption temperature (down to $200{ }^{\circ} \mathrm{C}$ ). The carbon nanopowder was inserted within the device from a fluidic solution made of water and then dried in oven at 100 ${ }^{\circ} \mathrm{C}$ for evaporating the liquid phase. The heating element of the device could also be used for evaporating the solvent $[2$, 3].

\section{Test bench setup}

In this study, benzene vapor in dry air has been chosen as target gas. The test bench used to validate our modelling results is made of three mass flow controllers. In fact, low concentrations of benzene, between 10 and $500 \mathrm{ppb}$, are generated using a gas cylinder containing $100 \mathrm{ppm}$ of benzene in air and a dilution-stage made of two mass-flow controllers connected 
to air cylinders. Pressure sensors are placed upstream and downstream of the mass-flow controllers for checking the correct operation of the setup. A "TGS 2620" Figaro sensor was used to detect benzene molecules. The first tests were dedicated to the validation of the setup and were performed using a preconcentrator not filled with an adsorbent material. They consisted of injecting $100 \mathrm{ppm}$ of benzene through the empty preconcentrator, which resulted directly in a breakthrough since there was no adsorption of benzene. Indeed, when $100 \mathrm{ppm}$ benzene was injected in the device, the sensor detects the right concentration without any retention time and no desorption peak was then observed during the heating step of device. All the other experiments were conducted using micro-preconcentrators filled with $1 \mathrm{mg}$ of carbon nanopowder unless otherwise stated.

\section{Experimental parameters}

Given the fact that the main goal of this modelling is to maximize the PF, all parameters on which relies the latter were varied in order to find the optimum experimental parameters for the maximization of the PF. Therefore, the adsorption and desorption flow rates were varied between 33 and $333 \mathrm{~mL} / \mathrm{min}$ whereas the heating rate during the desorption was varied between 5 and $160{ }^{\circ} \mathrm{C} / \mathrm{min}$, depending on the type of experiments to conduct. Meanwhile, the detection volume of the sensor was also decreased to determine the ideal sampling volume.

\section{ADSORTION AND DESORPTION MODELLING APPROACHES}

Numerical modelling of adsorption-desorption in a preconcentration can be implemented in two main approaches:

- A simplified approach in zero dimension, not taking into account the geometry of the micropreconcentrator, considers the device as a "punctual box" with a limited adsorption capacity (depending on the temperature). This modelling version of adsorption is simple and can be implemented in a spreadsheet program. Nevertheless, it does not allow describing the breakthrough curve since with this approach the breakthrough is abrupt (step) as soon as the "box" capacity is reached.

- A more complex approach in one dimension which, in addition to the time dimension, takes into account the one-dimensional geometry of the micropreconcentrator. It allows modelling the breakthrough either by finite differences even for a nonequilibrium system or by finite elements but only for a system in thermodynamic equilibrium. The Table 2 summarizes the different conditions of the adsorption-desorption modelling.

The choice of the thermodynamic equilibrium state by using the equations of the adsorption isotherms (Langmuir, BET, Dubinin ...) simplifies the modelling of the system. But this choice supposes that the system has "no memory effect". Indeed, the desorption is activated as soon as the gas injection stops even at room temperature, since in thermodynamic equilibrium, the recovery rate is zero when the pressure is zero. Therefore, there is no possibility to model the desorption phase at equilibrium conditions.
The choice of non-equilibrium conditions suggests implementing the model on base of equations of adsorption and desorption kinetics. This method will allow modelling as well the adsorption as the desorption using iterative calculations. However, in this complex case, we could develop only a monolayer model as Langmuir type.

Table 2: summary of the different parameters for adsorptiondesorption modelling.

\begin{tabular}{|c|c|c|}
\cline { 2 - 3 } \multicolumn{1}{c|}{} & Zero Dimension & One Dimension \\
\hline $\begin{array}{c}\text { Adsorption iso- } \\
\text { therms equations } \\
\text { Thermodynamic } \\
\text { equilibrium }\end{array}$ & $\begin{array}{c}\text { Langmuir BET } \\
\text { or Dubinin Theo- } \\
\text { ries }\end{array}$ & $\begin{array}{c}\text { Finite elements }+ \\
\text { Langmuir, BET or } \\
\text { Dubinin ... }\end{array}$ \\
\hline $\begin{array}{c}\text { Adsorption- } \\
\text { desorption kinetic } \\
\text { equations } \\
\text { Non-equilibrium }\end{array}$ & $\begin{array}{c}\text { By Finite differ- } \\
\text { ences } \\
\text { One variable } t \\
\text { Langmuir only }\end{array}$ & $\begin{array}{c}\text { By Finite differ- } \\
\text { ences, } \\
\text { Two variables } t, x \\
\text { Langmuir only }\end{array}$ \\
\hline
\end{tabular}

\section{Langmuir theory}

The fundamental theory of gas adsorption on solid is the first model implemented; it was proposed by Langmuir [9, 12, 13, 14] in 1918 and is based on three key hypotheses:

- a monolayer adsorption localized on sites welldefined and equivalents;

- $\quad$ an uniformity of the adsorption surface;

- and finally, no interaction between adsorbed molecules (Figure 2).

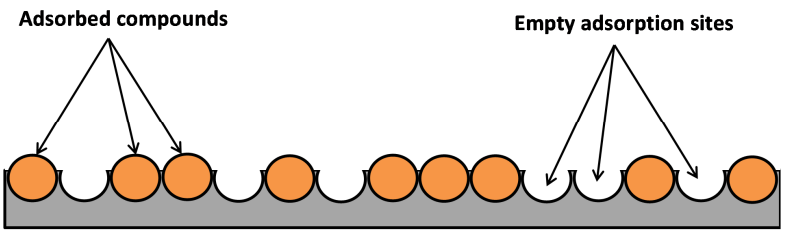

Figure 2: Monolayer adsorption model representing the adsorption sites and the arrangement of the adsorbed gas molecules.

Indeed, if $s$ is the adsorption site, $G$ the gas molecules adsorbed, for a recovery rate $\theta$ and a number $\mathrm{N}_{0}$ of available adsorption sites per unit of surface, the equation of adsorption is represented by:

$$
G+s \stackrel{\text { adsorption }}{\longrightarrow} G-s
$$

In thermodynamic equilibrium, the adsorption rate is equal to the desorption rate and the recovery rate is obtained from the equation:

$$
\theta=\frac{\alpha C}{1+\alpha C} \text { (4) with } \alpha=\frac{k_{a}}{k_{d}}
$$

where $\mathrm{k}_{\mathrm{a}}$ and $\mathrm{k}_{\mathrm{d}}$ are the constants of adsorption and desorption rates (described in equations 14 and 15). 


\section{Breakthrough time modeling}

The breakthrough time means the time after which a pollutant gas in concentration $C_{i n}$ injected through an adsorbent bed "begins" to be detected out of this adsorbent bed at the certain concentration $\left(\mathrm{C}_{\text {out }}\right)$. It can be evaluated from multiple models including the Wheeler-Jonas one $[4,6,15]$ which remains the most commonly used, for the adsorption of volatile organic compounds (VOC) :

$$
t_{b}=\frac{M \cdot W e}{Q \cdot C_{\text {in }}}-\frac{W e \cdot \rho b}{k v \cdot C_{\text {in }}} \ln \left(\frac{C_{\text {in }}-C_{\text {out }}}{C_{\text {out }}}\right)
$$

In this equation, $\mathrm{t}_{\mathrm{b}}$ is the breakthrough time $(\mathrm{min})$ to reach $\mathrm{C}_{\text {out }}$, $\mathrm{M}$ the weight of the carbon bed $\left(\mathrm{g}_{\text {carbon }}\right)$, We the equilibrium adsorption capacity $\left(\mathrm{g} / \mathrm{g}_{\text {carbon }}\right), \mathrm{Q}$ the volumetric flow rate $\left(\mathrm{cm}^{3} / \mathrm{min}\right), \mathrm{C}_{\text {in }}$ the contaminant concentration in air $\left(\mathrm{g} / \mathrm{cm}^{3}\right)$, $\mathrm{C}_{\text {out }}$ the chosen breakthrough concentration $\left(\mathrm{g} / \mathrm{cm}^{3}\right), \rho_{\mathrm{b}}$ the bulk density of the carbon bed $\left(\mathrm{g}_{\text {carbon }} / \mathrm{cm}^{3}\right)$ and $\mathrm{kv}$ the overall adsorption rate coefficient $\left(\mathrm{min}^{-1}\right)$.

From this Wheeler-Jonas model for breakthrough time $t_{b}$ characterization, the adsorption capacity We is defined by the relation:

$$
W_{e}=W_{o} \cdot d L \cdot \exp \left(-\frac{B T^{2}}{\beta^{2}}\left(\frac{C s}{C \text { in }}\right)\right)
$$

Where $\mathrm{W}_{\mathrm{o}}\left(\mathrm{cm}^{3} / \mathrm{g}\right)$ is the microporous volume of the adsorbent, $\mathrm{dL}\left(\mathrm{g} / \mathrm{cm}^{3}\right)$ the liquid density of the VOC, B $\left(\mathrm{K}^{-2}\right)$ structural constant of the adsorbent, $\mathrm{T}(\mathrm{K})$ the experimental temperature, $\beta$ the coefficient of affinity between adsorbent and VOC, $\mathrm{C}_{\mathrm{s}}\left(\mathrm{g} / \mathrm{cm}^{3}\right)$ and $\mathrm{C}_{\mathrm{in}}\left(\mathrm{g} / \mathrm{cm}^{3}\right)$ concentrations of VOCs respectively at the vapor saturation pressure and in the air (vector gas).

The adsorption rate coefficient $\mathrm{k}_{\mathrm{v}}\left(\mathrm{min}^{-1}\right)$ is determined from the molecular weight of VOC $\mathrm{M}_{\mathrm{w}}(\mathrm{g} / \mathrm{mol})$, the average diameter of adsorbent particles $d_{p}(\mathrm{~cm})$, the coefficient of affinity between adsorbent and VOC $\beta$ and the velocity through the adsorbent bed $\mathrm{V}_{\mathrm{L}}$ :

$$
k v=800 \cdot \beta^{0.33} \cdot V_{L}^{0.75} \cdot d_{p}^{-1.5} \cdot \sqrt{\left(\frac{W e}{M w}\right)}
$$

However, this model is applicable only for concentrations verifying the relation $\frac{\text { Cout }}{C \text { in }}<4 \%$.

The wheeler-Jonas breakthrough model seems more appropriate for devices with short length and large cross section of adsorbent bed such as gas masks. Thus, the idea in this paragraph is to implement a simple and more appropriate model in case of micro-preconcentrator with thin adsorbent bed and longer resident time.

As mentioned previously, the breakthrough time depends on the adsorption capacity of the adsorbent bed and the concentration and flow rate of the target gas. Insofar as we have always observed a relatively sudden breakthrough, in a first approximation, we can consider that the breakthrough time corresponds to the time required by the target gas to fill all available adsorption sites of the adsorbent material.
Indeed, if $\mathrm{N}(\mathrm{t})$ is the number of gas molecules injected into the adsorbent bed for a period of time $t$, by supposing a complete adsorption of the injected gas molecules on the adsorbent, $\mathrm{N}(\mathrm{t})$ is then given by:

$$
N(t)=f \cdot C_{i n} \cdot t
$$

With $f$ the flow rate during the adsorption and $\mathrm{C}_{\mathrm{in}}$ the concentration of the target gas (supposed constant).

If $\mathrm{N}_{\mathrm{m}}$ is the maximum number of gas molecules which can be adsorbed per unit of surface on the adsorbent bed at a given temperature, so at the breakthrough time $t_{b}$, there is equality between the injected quantity of gas and the adsorption capacity of the adsorbent:

$$
N_{m}=f \cdot C_{i n} \cdot t_{b} \Rightarrow t_{b}=\frac{N_{m}}{f \cdot C_{i n}}
$$

Furthermore, it should be noted that the breakthrough time is often reported with an outlet concentration $\mathrm{C}_{\text {out }}$ meaning the threshold concentration at which the breakthrough is considered effective. This concentration $\mathrm{C}_{\text {out }}$ related to the limit of detection of the sensing system shows that the assumption of complete adsorption of the injected gas molecules is approximate and it goes the same for a "perfect" breakthrough.

Moreover, if $\mathrm{N}_{\mathrm{o}}$ is the maximal number of available adsorption sites on the adsorbent bed and by assuming that the system is in thermodynamic equilibrium during adsorption phase (approximation of not activated adsorption), the number of occupied adsorption sites $\mathrm{N}_{\mathrm{m}}$ on the adsorbent bed could be expressed using the recovery rate $\theta$ from Langmuir model (equation 4):

$$
N_{m}=N_{0} \cdot \theta
$$

Following the equation 4 describing the recovery rate and equations 9 and 10 , the breakthrough time is then given by:

$$
t_{b}=\frac{\alpha N_{0}}{f \cdot(1+\alpha C)} \text { (11) with } \mathrm{C}_{\text {in }} \text { equivalent to } \mathrm{C} \text {. }
$$

Two limit cases can be deduced from this equation 11:

$$
\text { Case 1: } \alpha C>>1 \Rightarrow \theta \cong 1 \Rightarrow t_{b}=\frac{N_{0}}{f \cdot C} \approx \frac{1}{C}
$$

This case describes both the use of relatively high concentrations of gas and adsorbents having high adsorption rate such as activated carbon or carbon nanotubes. In this case, the breakthrough time observed is an inverse function of concentration. Higher the concentration is, shorter is the breakthrough.

$$
\text { Case 2: } \alpha C \ll<\Rightarrow \theta \cong 0 \Rightarrow t_{b}=\frac{\alpha N_{0}}{f}=\text { Cte }
$$

This case symbolizes experimentations conduced at low concentrations of target gas and with adsorbents having low adsorption rate too. The breakthrough time obtained in this case is independent to the concentration and depends only on the flow rate and the length of the adsorbent bed.

This breakthrough model is in good correlation with our experimental results on breakthrough time measurements obtained from a $\mu$-GP filled with $10 \mathrm{mg}$ of carbon and tested at 
different concentrations of benzene injected at a flow rate $f$ of $166 \mathrm{~mL} / \mathrm{min}$. This is particularly true for the Langmuir model which reproduces closely the experimental points (Figure 3 ). The parameters used in the Langmuir model are $\alpha=5.81$ and $\mathrm{N}_{0}=1.10^{+4}$ when $\mathrm{t}_{\mathrm{b}}$ is in $\mathrm{min}, f$ in $\mathrm{mL} / \mathrm{min}$ and $\mathrm{C}$ in $\mathrm{ppm}$ whereas the $\frac{1}{C}$ model is implemented with a constant $\mathrm{k}$ $\left(k=\frac{N_{0}}{f}\right)$ of 40.38 .

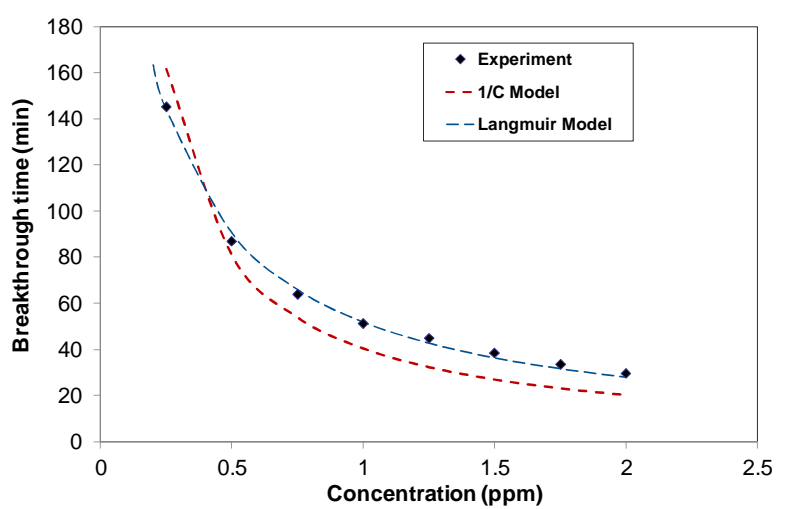

Figure 3: Comparison between the experimental breakthrough times at different concentrations and the fitted theoretical models (Langmuir and 1/C) for $10 \mathrm{mg}$ of carbon.

\section{Adsorption - Desorption modeling algorithms}

\section{Zero dimension modelling $(O D)$}

The zero dimension models proposed in the literature are generally based on systems in thermodynamic equilibrium using Langmuir, BET or Dubinin adsorption isotherms [15, $16,17]$. Most of these OD models were developed to predict the gas masks or cleaners saturation. The zero dimension and non-equilibrium model developed in this paragraph is based on the finite differences method with a single variable: the time $t$ and no spatial variable. In this model, we suppose that the adsorption of gas molecules is monolayer type i.e. the adsorption sites of the solid, energetically equivalent, may contain only one molecule per site and there is no interaction between different molecules adsorbed (Theory of Langmuir).

The reactions of adsorption and desorption, characterized by their rates $\mathrm{V}_{\mathrm{a}}$ and $\mathrm{V}_{\mathrm{d}}$, are thermally activated and their activation energies are respectively $E_{a}$ and $E_{d}$.

$$
\begin{aligned}
& V_{a}=\frac{d \theta_{a}}{d t}=k_{a} \cdot C N_{0}(1-\theta) \quad \text { with } \quad \mathrm{k}_{\mathrm{a}}=\mathrm{k}_{\mathrm{a}}^{0} \cdot \exp \left(\frac{-\mathrm{E}_{\mathrm{a}}}{R T}\right) \\
& V_{d}=\frac{d \theta_{b}}{d t}=k_{d} \cdot N_{0} \theta \text { with } \mathrm{kd}_{\mathrm{d}}=\mathrm{k}_{\mathrm{a}}^{0} \cdot \exp \left(\frac{-\mathrm{E}_{\mathrm{d}}}{R T}\right)
\end{aligned}
$$

Where $\mathrm{k}_{\mathrm{a}}$ and $\mathrm{k}_{\mathrm{d}}$ are the adsorption and desorption coefficients, respectively.

The adsorption phase is often considered "inactivated" i.e. it occurs spontaneously and instantaneously even at room temperature (since $\mathrm{E}_{\mathrm{a}}<<\mathrm{RT}$ )
If ni is the number of molecules adsorbed at time $t$, then at time $\mathrm{t}+\mathrm{dt}$, we have:

$$
\begin{aligned}
& t \longrightarrow t+d t \\
& n_{i} \longrightarrow d_{t} \longrightarrow n_{i}+d n
\end{aligned}
$$

But $\mathrm{dn}$ is given from the adsorption and desorption rates $\left(\mathrm{V}_{\mathrm{a}}\right.$ and $\mathrm{V}_{\mathrm{d}}$ ) by the relation:

$$
\begin{gathered}
\mathrm{dn}=\left(V_{a}-V_{d}\right) \cdot d t(17) \\
\mathrm{dn}=\left[\mathrm{k}_{\mathrm{a}}^{0} \cdot \mathrm{C} \cdot N_{0}\left(1-\theta_{i}\right) \cdot \exp \left(\frac{-\mathrm{E}_{\mathrm{a}}}{R T}\right)-\mathrm{k}_{\mathrm{d}}^{0} \cdot N_{0} \theta_{i} \cdot \exp \left(\frac{-\mathrm{Ed}_{\mathrm{d}}}{\mathrm{RT}}\right)\right] \mathrm{dt}
\end{gathered}
$$

As in a monolayer adsorption-desorption model, the recovery rate $\theta \mathrm{i}$ is the ratio between the number of adsorbed particles $\left(\mathrm{n}_{\mathrm{i}}\right)$ and the number of available site in the same element $\mathrm{i}$ $\left(\mathrm{N}_{0}\right)$ :

$$
\theta i=\frac{n_{i}}{N_{0}}(\text { from equation } 10)
$$

In case of adsorbents with high adsorption capacity (which is of interest for the present application), the adsorption is not activated and does not depend on temperature, either:

$$
\begin{gathered}
\exp \left(\frac{-\mathrm{Ea}}{R T}\right) \approx 1(19) . \\
\theta_{i+1}=\theta_{i}+\left(\mathrm{k}_{\mathrm{a}}^{0} \cdot C \cdot\left(1-\theta_{i}\right)-\theta_{i} k_{d}^{0} \exp \left(\frac{-E_{d}}{R T}\right)\right) \cdot \mathrm{dt} \quad \in[0,1]
\end{gathered}
$$

The desorption activation energy can be calculated from the difference of temperatures between the maximum of desorption peaks obtained when operating at different heating rates (see equation 35 hereafter).

This zero dimension model has "very limited" interest for the adsorption phase and does not allow predicting the breakthrough curve.

However, this model fits well with our experimental desorption peak obtained from a $\mu$-GP filled with $1 \mathrm{mg}$ of carbon after an adsorption of $250 \mathrm{ppb} @ 5 \mathrm{~min}$ of benzene and a desorption at $20^{\circ} \mathrm{C} / \mathrm{min}$ and $100^{\circ} \mathrm{C} / \mathrm{min}$ (Figure 4). The parameters $\mathrm{K}_{\mathrm{d}}^{0}$ and $\mathrm{E}_{\mathrm{d}}$ used in this model were calculated from equations 35 and 36 (below) and are equal to $\approx 7.10^{+3}$ and $4.10^{+4} \mathrm{~J}$, respectively. This model could easily be implemented in an Excel spreadsheet 


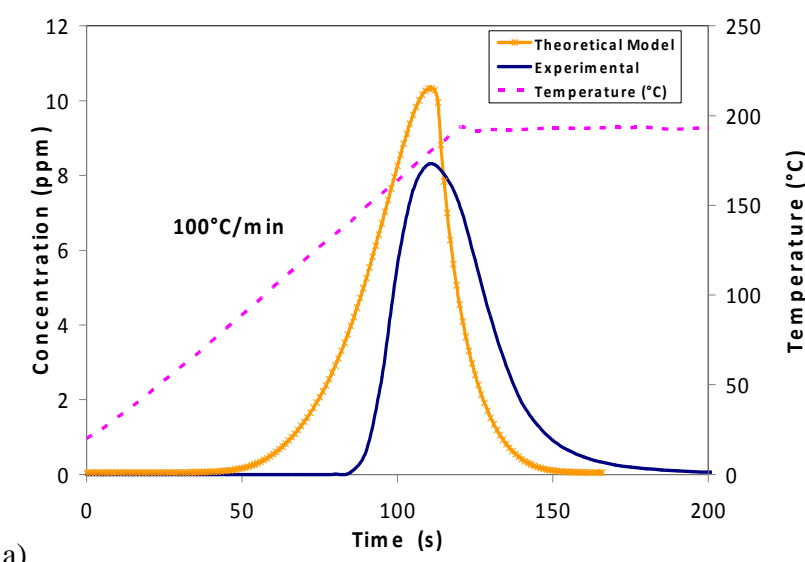

a)

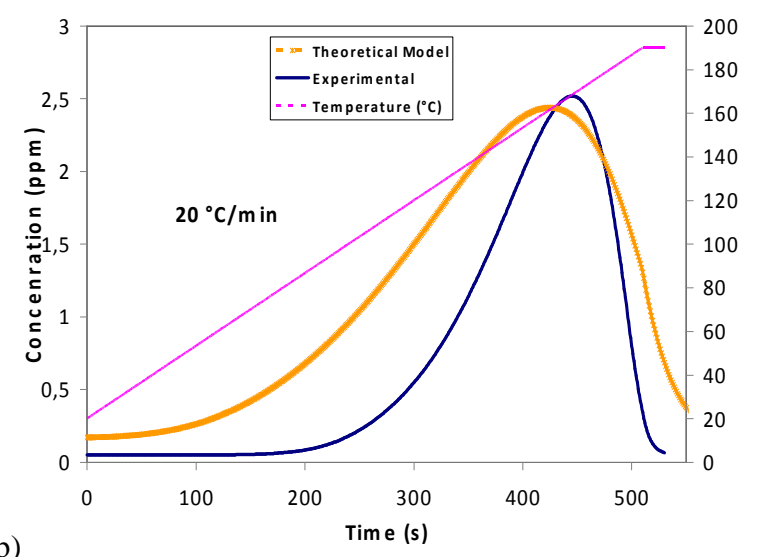

Figure 4: Comparison between experimental data obtained from a $\mu$-GP filled with $1 \mathrm{mg}$ of carbon after an adsorption of $250 \mathrm{ppb}$ during $5 \mathrm{~min}$ of benzene at a flow rate of $166 \mathrm{~mL} / \mathrm{min}$ and a desorption at a flow rate of $33 \mathrm{~mL} / \mathrm{min}$ at a) $20{ }^{\circ} \mathrm{C} / \mathrm{min}$ and b) 100 ${ }^{\circ} \mathrm{C} / \mathrm{min}$ and theoretical "OD" model of desorption fitted to the experimental conditions.

\section{One dimension modelling (1D)}

Several one-dimension adsorption-desorption models have been developed in recent years and are mostly based on a discretization of the system in finite elements or finite differences $[7,8]$. Among these models based on finite elements, we can enumerate the one implemented by A. Joly and L. Perrard [8] based on a thermodynamic equilibrium system. This model is governed by a system of equations:

$$
\left\{\begin{array}{l}
-F \frac{\partial C}{\partial x}=\rho_{b} \cdot S \frac{\partial W}{\partial t} \\
\frac{\partial W}{\partial t}=k_{T}\left(C-C_{s}\right)
\end{array}\right.
$$

in which $\mathrm{F}, \mathrm{C}, \mathrm{Cs}, \mathrm{W}, \rho_{\mathrm{b}}, \mathrm{S}$ and $\mathrm{k}_{\mathrm{T}}$ correspond to the target gas flow rate, concentration inside the adsorbent bed and concentration on the surface, the quantity of gas adsorbed per mass unit of adsorbent, the density of the adsorbent bed, the crosssection of the adsorbent bed and a constant related to the temperature of the bed, respectively.

However, this model is applicable only for systems in thermodynamic equilibrium since the concentration Cs is accessible only from the adsorption isotherms using the relation dependence of $\mathrm{W}$ versus Cs. Their model allows predicting the adsorption phase only at constant concentration and temperature and thus cannot describe the desorption phase.

Therefore, we have implemented a model in one dimension which treats the adsorption in more general context, taking into account the non-equilibrium case. In addition to the adsorption-desorption kinetic equation, this model includes the transport equations and allows predicting both the breakthrough curve and the adsorption-desorption peak. We have also established the diffusion equations of the gas phase. Nevertheless, the influence of this effect remained negligible for our case. Our model is based on the discretization of the system by finite elements.

To develop a simple mathematical model of gas adsorption inside the micro-preconcentrator, we assumed that the microdevice area is a parallelepiped with a defined volume, V. The absorbent particles are deposited uniformly in this volume. The target gas flows constantly (flow $f$ ) within the device and its concentration $\mathrm{C}$ varies gradually when flowing through the adsorbent because of the adsorption phenomena occurring in gas-solid interface (Figure 5).

This parallelepiped is divided into a set of identical volume elements, $\mathrm{dV}$, much smaller than the volume $\mathrm{V}$ of the microdevice. Each element of volume $\mathrm{dV}$ is characterized by the relationship:

$$
d V=S \cdot d x(22)
$$

where $\mathrm{S}$ and $\mathrm{dx}$ correspond to the effective section of the micro-preconcentrator and the length of the element of volume $\mathrm{dV}$, respectively.

If the micro-device has a total length $\mathrm{L}$, then:

$$
L=n \cdot d x(23)
$$

with $n$ the number of elements (typically, $n=50$ ). Each element $i$ with a volume $d V_{i}$ is defined by a gas concentration $C_{i}$, an adsorption recovery rate $\theta_{\mathrm{i}}$ and a number of pollutant molecules adsorbed $\mathrm{dn}_{\mathrm{i}}$.

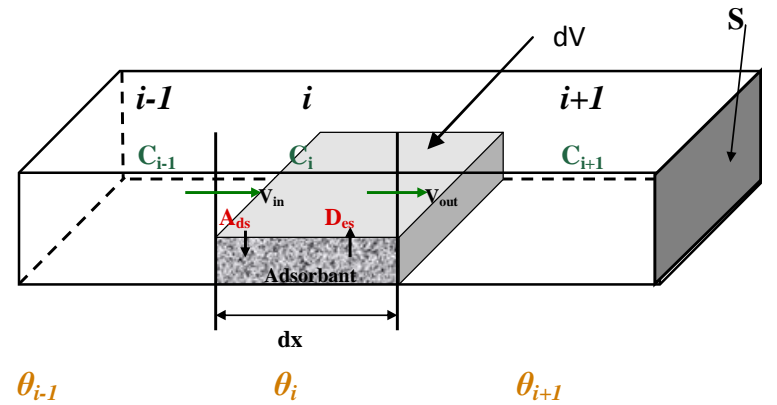

Figure 5: Diagram schematic of a preconcentrator box.

Since the recovery rate $\theta_{\mathrm{i}}$ symbolizes the number of occupied adsorption sites, its evolution during the period of time between $\mathrm{t}$ and $\mathrm{t}+\mathrm{dt}$ is given by the equation:

$$
\theta_{i}(t+d t)=\theta_{i}(t)+\frac{d n_{i}}{N_{0}}
$$

where $\theta_{\mathrm{i}}(\mathrm{t})$ is the recovery rate at time $\mathrm{t}$ and $\mathrm{dn}_{\mathrm{i}}$ the global variation of the quantity of molecules between $t$ and $t+d t$ within the $i^{\text {th }}$-element. 
This global variation of quantity of molecules is the sum of the transport, the adsorption and the-desorption variations between $\mathrm{t}$ and $\mathrm{t}+\mathrm{dt}$ within the $\mathrm{i}^{\text {th }}$-element:

$$
d n_{i}=d n_{i}^{t}+d n_{i}^{a}+d n_{i}^{d}
$$

The transport term is given by:

$$
d n_{i}^{t}=f \cdot\left(C_{i-1}-C_{i}\right) d t
$$

Following the Langmuir hypothesis concerning rates of adsorption and desorption, $\mathrm{V}_{\mathrm{a}}$ and $\mathrm{V}_{\mathrm{d}}$ (equations 14 and 15), the adsorption and desorption variation is expressed by:

$$
\begin{aligned}
& \text { Adsorption term: } d n_{i}^{a}=V_{a} C_{i}\left(1-\theta_{i}\right) \\
& \text { Desorption term: } d n_{i}^{d}=V_{d} \theta_{i}
\end{aligned}
$$

The diffusion term is negligible and the outlet concentration $\mathrm{C}_{\text {out }}$ is the gas concentration in the last element $\mathrm{i}+\mathrm{n}$. These equations are iteratively calculated for each element $i$ and for all steps of time dt.

For this kind of iterative calculation, the choice of the step of time $d t$ is of course very important:

- If dt is too large, the CFL (Courant-Friedrich-Lewy $[18,19])$ stability condition cannot be respected:

$$
f \text {.dt }<\text { S.dx }
$$

With $f, \mathrm{~S}$ and $\mathrm{dx}$ the flow rate, the effective section of the micro-preconcentrator and the length of the element of volume $\mathrm{dV}$, respectively

If $\mathrm{dt}$ is too low, calculations may take long time, and the transport term could create a problem called "numerical diffusion" [18].

This model of adsorption-desorption in 1D can be easily implemented in a classical langage like $\mathrm{C}$ or Matlab. In our case, we have used the Labview graphical computer language.

The characteristics of the adsorbent and the adsorbed gas are defined on this model from the activation energy of desorption $\mathrm{E}_{\mathrm{d}}$ and the frequency factors $\mathrm{k}_{\mathrm{a}}$ and $\mathrm{k}_{\mathrm{d}}$ which can be determined from a thermal programmed desorption with different heating rates.

If $T_{m}$ and $t_{m}$ define the temperature and the time of the maximum of a desorption peak respectively, then the derivative of the desorption function is zero at the period $\mathrm{t}=\mathrm{tm}$ :

$$
\left(\frac{d V_{d}}{d T}\right)_{T=T m}=\left(\frac{d t}{d T} \cdot \frac{d V_{d}}{d t}\right)_{t=t m}=0
$$

Since the temperature of the $\mu$-GP increases linearly with the heating rate, $a$, thus the temperature can be determined by:

$$
T=T^{0}+a \cdot t
$$

By supposing Ed and $\mathrm{Kd}$ independent on the temperature and following the equation (15), the relation 30 could be expressed by:

$$
\left(\frac{d V_{d}}{d T}\right)_{T=T m}=\frac{1}{a}\left(\frac{d V_{d}}{d t}\right)_{t=t m}=0 \Rightarrow \frac{E_{d}}{R \cdot T_{m}^{2}}=\left(\frac{k_{d}}{a}\right) \cdot \exp \left(-\frac{E_{d}}{R \cdot T_{m}}\right)
$$

The activation energy and frequency factor of the desorption could be calculated from two different heating rates during the desorption of the preconcentrator. So, if $\mathrm{T}_{1}$ and $\mathrm{T}_{2}$ characterize temperatures corresponding to maximum of the desorption peak for two different heating rates, $\mathrm{a}_{1}$ and $\mathrm{a}_{2}$, respectively, one will obtain:

$$
\begin{aligned}
\frac{E_{d}}{R \cdot T_{1}^{2}} & =\left(\frac{k_{d}}{a_{1}}\right) \cdot \exp \left(-\frac{E_{d}}{R \cdot T_{1}}\right) \\
\frac{E_{d}}{R \cdot T_{2}^{2}} & =\left(\frac{k_{d}}{a_{2}}\right) \cdot \exp \left(-\frac{E_{d}}{R \cdot T_{2}}\right)
\end{aligned}
$$

In case that the standard deviation, $\Delta \mathrm{T}$, between $\mathrm{T}_{1}$ and $\mathrm{T}_{2}$ is less than $10 \mathrm{~K}, \Delta \mathrm{T}$ is negligible in regard to $\mathrm{T}_{\mathrm{Av}}$ the average of $\mathrm{T}_{1}$ and $\mathrm{T}_{2}$. The division and multiplication between relations 33 and 34 will lead respectively to:

$$
\begin{aligned}
& E_{d} \approx\left(\frac{R \cdot T_{A v}^{2}}{\Delta T}\right) \cdot \operatorname{Ln}\left(\frac{a_{1}}{a_{2}}\right) \\
& k_{d} \approx\left(\left(a_{1} \cdot a_{2}\right) \cdot \frac{E_{d}}{R \cdot T_{A v}^{2}}\right) \cdot \exp \left(\frac{E_{d}}{R \cdot T_{A v}}\right)
\end{aligned}
$$

This implemented model was used to predict the adsorption curve of activated carbon tested in experimental conditions close to the model parameters. Indeed, the parameters $\mathrm{k}^{0} \mathrm{a}, \mathrm{k}^{0} \mathrm{~d}$, and $E_{d}$ of $1 D$ model were defined from calculation at 10 , $1.10^{+10}$ and $9.10^{+4}$, respectively, whereas $\mathrm{Ea}$ is fixed at zero since no activation energy is needed for the adsorption. At these conditions, the 1D model describes correctly the breakthrough shape since the theoretical curve obtained at $400 \mathrm{ppb}$ follows the same trend than the experimental one obtained in identical conditions (Figure 6).

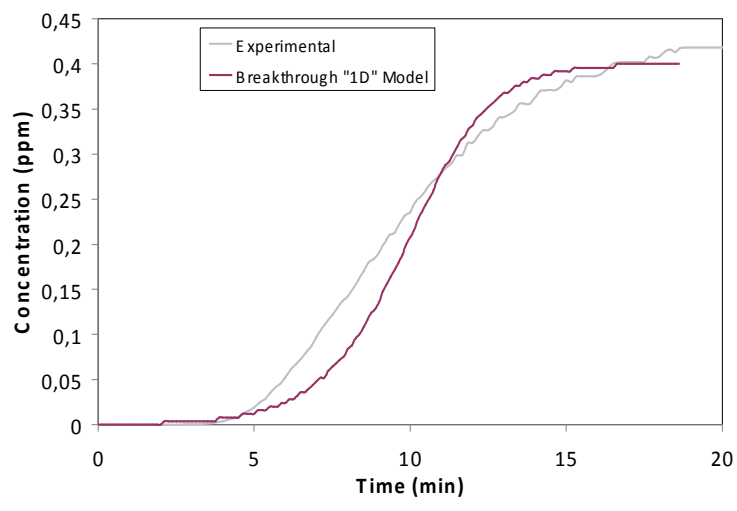

Figure 6: Breakthrough curve obtained from a $\mu$-GP filled with $10 \mathrm{mg}$ of carbon after an adsorption of $400 \mathrm{ppb}$ of benzene at $166 \mathrm{~mL} / \mathrm{min}$ : comparison between experimental and theoretical results, "1D" model.

The effect of the heating rate during the desorption was tackled through series of tests realized at the same experimental conditions, except for the heating rate which was varied. Indeed, these experiments have demonstrated the fact that faster is the heating rate, higher is the desorption peak. Therefore, the desorption height at a heating rate of $160{ }^{\circ} \mathrm{C} / \mathrm{min}$ is 12 times higher than the one obtained at $50{ }^{\circ} \mathrm{C} / \mathrm{min}$ (Figure 7). 


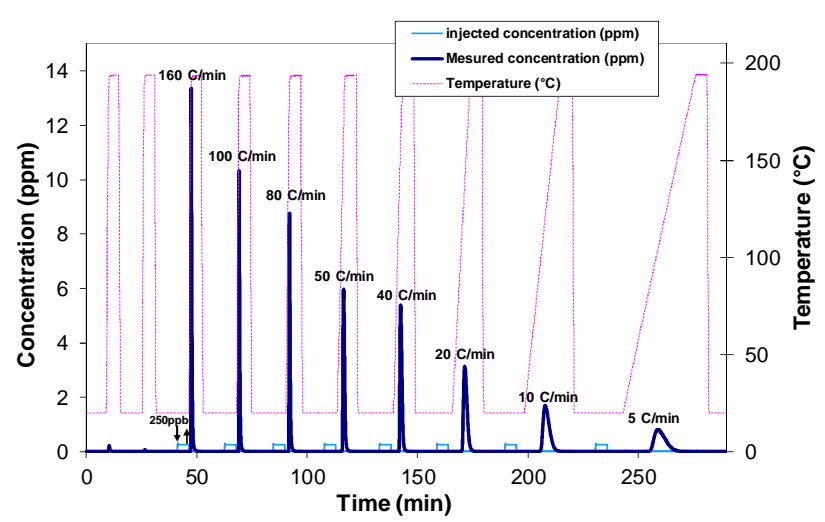

Figure 7: Experimental desorption peak obtained from a $\mu$-GP filled with $1 \mathrm{mg}$ of carbon after an adsorption of $250 \mathrm{ppb} @ 5 \mathrm{~min}$ of benzene at a flow rate of $166 \mathrm{~mL} / \mathrm{min}$ and desorbed at different heating rate from 5 to $160{ }^{\circ} \mathrm{C} / \mathrm{min}$ with a desorption flow of $33 \mathrm{~mL} / \mathrm{min}$.

Our 1D model was also used to predict the effect of the heating rate on the desorption peak height. This model shows a good correspondence with experiments conducted at different heating rates from 5 to $160{ }^{\circ} \mathrm{C} / \mathrm{min}$ obtained from a $\mu$-GP filled with $1 \mathrm{mg}$ of carbon after an adsorption of 250 ppb@5min of benzene (Figure 7). However, no significant improvement is observed in regards to the "OD" model (Figure 4).

\section{INFLUENCE OF THE FLOW RATE AND OF THE DETECTION SYSTEM}

In order to test the effect of the desorption flow rate on the PF, several cycles of preconcentration were done at various desorption flow rates. The results obtained are shown in figure 8 .

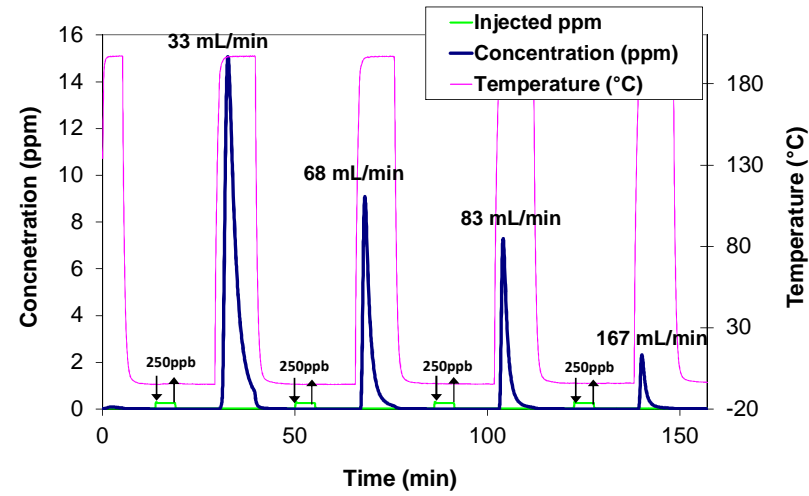

Figure 8: Experimental desorption peak obtained from a $\mu$-GP filled with 1mg of carbon after an adsorption of $250 \mathrm{ppb} @ 5 \mathrm{~min}$ of benzene at a flow rate of $166 \mathrm{~mL} / \mathrm{min}$ and desorbed at $160{ }^{\circ} \mathrm{C} / \mathrm{min}$ with different desorption flow rates (f) from 33 to $166 \mathrm{~mL} / \mathrm{min}$.

These experiments confirmed that the concentration at the outlet of the micro-preconcentrator is decreasing with the desorption flow rate for flow rates greater than $33 \mathrm{~mL} / \mathrm{min}$ (figure 11). However, the case of very low gas flows should be taken into consideration because of the detection volume of the sensing system which may act as a dilution factor. Hence modelling the sensor response is crucial for understanding the effect of low flow rates on the PF of the couple $\mu$-GP/Sensor.

Like any detector, the sensor used in this study takes up a certain volume of injected gas. So, a large detection volume (up to $10 \mathrm{ml}$ ) may lead to a significant dilution of the desorbed gas and therefore may lower the sensor sensitivity. Thus, the optimization of the detector response could be achieved only in the sense of minimizing this sampling volume.

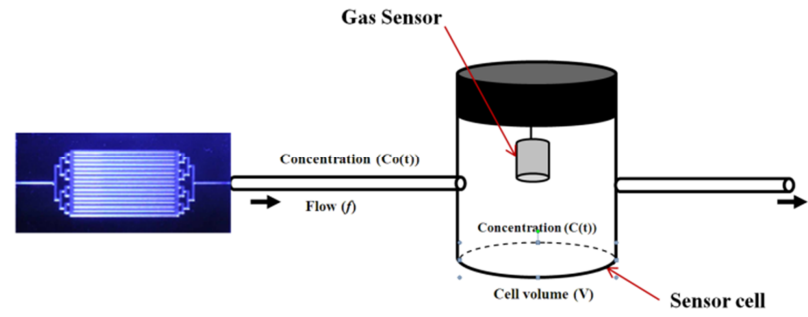

Figure 9: Schematic diagram showing the interconnection between the micro-preconcentrator and the detection system.

By supposing that the sensor is immersed in this continuously stirred cell volume V (Figure 9), one can calculate, for a give flow rate $f$, the variation of the gas concentration seen by the sensor after period of time $\Delta \mathrm{t}$ :

$$
C(t+\Delta t)=C(t)+\left[C_{0}(t)-C(t)\right] \frac{f}{V} \Delta t
$$

This established formula shows that the gas concentration $\mathrm{C}(\mathrm{t})$ seen by the sensor passes through a one order low-pass filter with a constant time $\tau$ equal to $\frac{V}{f}$. This low-pass filter could reduce the amplitude of the detector response if the constant time $\tau$ is greater than the duration of the desorption peak $\boldsymbol{t}_{\boldsymbol{d}}$. This diminution of amplitude is the consequence of the spreading of the desorption peak since the width of the latter increases while its total surface remains constant. The theory of first order filter shows that:

- $\quad$ if $\boldsymbol{t}_{\boldsymbol{d}}>\boldsymbol{\tau}$, the amplitude of desorption is inversely proportional to $\boldsymbol{t}_{\boldsymbol{d}}$. A high heating rate is enough to maximize the PF.

- If $\boldsymbol{t}_{\boldsymbol{d}}>\boldsymbol{\tau}$ although the PF of the preconcentrator is inversely proportional to the flow rate, $f$, it is useless to decrease $f$ because this will lead to an increase of the constant time $\boldsymbol{\tau}$ and thus the diminution of the signal amplitude by the low-pass filter. In this case, the best solution for increasing the PF is to minimize the detection volume of the sensor.

If $t_{d}<\tau$, the effect of the low-pass filter is preponderant and thus a reduction of the sampling volume $\mathrm{V}$ and/or an increase of the flow rate are suggested for diminishing the constant $\boldsymbol{\tau}$. For that reason, we have integrated the outlet of the preconcentrator in the sensor packaging (Figaro, TGS 2620) in order to reduce considerably the detection volume (V) from $25 \mathrm{~mL}$ to $0.2 \mathrm{~mL}$ (Figure Figure 10). 


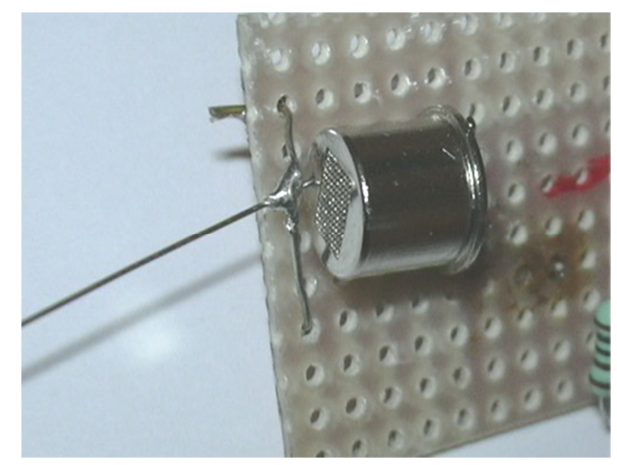

Figure 10: Figaro metal oxide (MOX) sensor with micro-channel capillary connected through its packaging.

However, changing the flow rate during the experiments causes temperature fluctuations on the sensing layer of the sensor and thus affects dramatically the sensitivity and the response time of the sensor. Therefore, a calibration of the sensor in terms of flow rate is needed to compensate these variations. Another solution is to change the nominal heating voltage of the sensor in order to maintain constant the temperature of the sensing layer despite flow rates changes (the solution we have chosen).After the calibration of the sensors, some experiments have been done for confirming the existence of an optimal flow. The optimal flow need to be not too small to avoid a reduction of sensor response and not too high to avoid a dilution of the desorbed quantity of molecules. For our preconcentrator and experimental setup, this optimal flow rate has been found between 20 and $40 \mathrm{~mL} / \mathrm{min}$. Moreover, we have chosen a flow of $33 \mathrm{~mL} / \mathrm{min}$ for some practical reasons linked to the dependence of the sensor sensitivity on the flow rate (Figure $11)$.

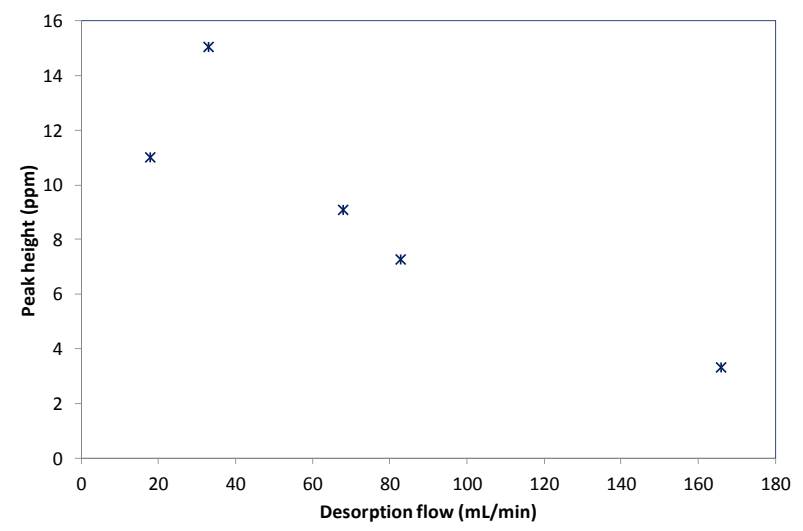

FIGURE 11: Maximum concentration of benzene versus desorption flow rate obtained from a $\mu$-GP filled with $1 \mathrm{mg}$ of carbon after an adsorption of $250 \mathrm{ppb} @ 5 \mathrm{~min}$ of benzene with a flow rate of $167 \mathrm{~mL} / \mathrm{min}$ and desorbed at $160{ }^{\circ} \mathrm{C} / \mathrm{min}$ and with a "modified" Figaro sensor.

\section{CONCLUSION}

The good correlation between the theoretical models and the complete experimental preconcentration cycle obtained with a micro gas preconcentrator has been demonstrated. This model allows predicting the behavior of preconcentrators for many adsorbent - adsorbed gas couples (carbon-benzene, carbontoluene, carbon nanotubes-benzene, carbon nanotubesnitrobenzene, Tenax-xylene...) in any experimental conditions with only two experiments necessary to determine the key kinetic parameters (activation energy, frequency factor) to be included in the model. However, the implemented models cannot describe all adsorption forms because it is essentially based on a monolayer adsorption model.

In summary, the maximization of the PF passes necessarily by:

- $\quad$ high adsorption flow rate $(\leq 333 \mathrm{~mL} / \mathrm{min}$ in our case) to accumulate the highest amount of the target gases in a short time, which is only limited by the pressure drop;

- an optimal desorption flow rate (about $33 \mathrm{~mL} / \mathrm{min}$ for our application) to avoid not only a dilution of the quantity of the desorbed molecules but also the lowpass filtering effect linked to the detection volume;

- a high heating rate (fixed at $160{ }^{\circ} \mathrm{C} / \mathrm{min}$ for our device) to avoid the spreading of the desorption peak;

- a low detection volume to avoid the low-pass effect of the latter.

\section{AUTHOR INFORMATION}

\section{Corresponding Author}

* Philippe Breuil, Phone : + 33 (0) 4774201 51, Email : pbreuil@emse.fr.

\section{REFERENCES}

[1] C. Pijolat, M. Camara, J. Courbat, J-P. Viricelle, D. Briand, N.F. de Rooij, Application of carbon nanopowders for gas micropreconcentrator. Sensors and Actuators B, 127 (2007) 179-185.

[2] E. H. M. Camara, P. Breuil, D. Briand, L. Guillot, C. Pijolat , N. F. de Rooij, Micro gas Preconcentrator in porous silicon filled with carbon adsorbent, Sensors and Actuators B 148 (2010) 610619.

[3] E. H. M. Camara, P. Breuil, D. Briand, N.F. de Rooij, C. Pijolat, A micro gas preconcentrator with improved performance for pollution monitoring and explosives detection, Analytica Chimica Acta 688 (2011) 175-182.

[4] M. J. G. Linders, E. P. J. Mallens, J. J. G. M. van Bokhoven, F. Kapteijn and J. A. Moulijn, Breakthrough of shallow activated carbon beds under constant pulsating flow, AIHA Journal, 64 (2003) 173-180.

[5] P. Lodewyckx, G.O. Wood, S.K. Ryu, The Wheeler-Jonas equation: a versatile tool for the prediction of carbon bed breakthrough times. Carbon 42 (2004) 1351-1355.

[6] L. A. Jonas, J. A. Rehrmann, The rate of gas adsorption by activated carbon, Carbon, 12 (1973) 95-101.

[7] Jufang Wu, Modeling adsorption of organic compounds on activated carbon: A multivariate approach. Thesis (2004) ISBN: 917305-697-9.

[8] A. Joly, V. Volpert and A. Perrard, Dynamic adsorption with FEMLAB, modeling breakthrough curves of gaseous polluants through activated carbon beds, Proceeding of COMSOL Multiphysics conference (2005) Paris.

[9] T. Sukaew, E. T. Zellers, Evaluating the dynamic retention capacities of microfabricated vapour preconcentrators as a function of flow rate. Sensors and Actuators B 183 (2013) 163- 171.

[10] P. R. Lewis, R. P. Manginell, D. R. Adkins, R. J. Kottenstette, D. R. Wheeler, Recent Advancements in the Gas-Phase MicroChemLab. IEEE Sensors journal, Vol. 6, N0. 3, June 2006.

[11] I. Gràcia, P. Ivanov, F. Blanco, N. Sabaté, X. Vilanova, X. Correig, L. Fonseca, E. Figueras, J. Santander, C. Cané, Sub-ppm gas sensor detection via spiral $\mu$-preconcentrator. Sensors and actuators B 132 (2008) 149-154.

[12] M. A. Slasli, Modélisation de l'adsorption par les charbons microporeux : Approche théorique t expérimentale. Thèse (2002) université de Neuchâtel-Suisse. 
[13] P. Le Cloirec, Adsorption en traitement de l'air. Technique de l'Ingénieur, G1770-1 à G1770-12.

[14] F. Rouquerol, L. Luciani, P. Llewellyn, R. Denoyel, J. Roouquerol, Texture des matériaux pulvérulents ou poreux. Technique de l'Ingénieur, P1050-1 à P1050-24.

[15]L. A. Jonas, E. B. Sansone, T. S. Farris, Prediction of activated carbon performance for binary vapor mixtures. Am. Ind. Hyg. Assoc. J. 44 (1983) 716-719.

[16] G. O. Wood, Review and comparaisons of D/R models of equilibrium adsorption of binary mixtures of organic vapors on activated carbons. Carbon 40 (2002) 231-239.
[17] X. Ye, N. Qi, Y. Ding, M. D. LeVan, Prediction of adsorption equilibrium using a modified D-R equation : Pure organic compounds on BPL carbon. Carbon 41 (2003) 681-686.

[18] F. Jedrzejewski, introduction aux méthodes numériques. Springer 2005.

[19] R. Courant, K. Friedrichs and H. Lewy, "On the partial difference equations of mathematical physics", IBM Journal, March 1967, pp. 215-234. 